\title{
RESEARCH ON COMPREHENSIVE EVALUATION INDEX SYSTEM OF PERFORMANCE AUDITING OF GOVERNMENTAL ECOLOGICAL ENVIRONMENT
}

\author{
LIU, X. J. ${ }^{1,2}-$ PAN, Y. $^{1 *}-$ YANG, J. $^{2}-$ ZHU, L. Z. ${ }^{1}-$ YING, L. M. $^{2}$ \\ ${ }^{1}$ School of Economics and Management, Fuzhou University, 350116 Fuzhou, PR China \\ ${ }^{2}$ School of Management, Wenzhou Business College, 325000 Wenzhou, PR China \\ ${ }^{*}$ Corresponding author \\ e-mail:panyan_fzdx@126.com
}

(Received $6^{\text {th }}$ Jun 2019; accepted 24 ${ }^{\text {th }}$ Oct 2019)

\begin{abstract}
A performance auditing evaluation problem of governmental ecological environment belongs to a Multiple Criteria Decision Making (MCDM) problem. However, we must use quantitative data to avoid inconsistency as well as to ensure the science and correctness of the decision in an evaluation index system of performance auditing. In this paper, we present a comprehensive evaluation index system of performance auditing of governmental ecological environment based on fuzzy Analytic Hierarchy Process (AHP) and Technique for Order Preference by Similarity to Ideal Solution (TOPSIS). Firstly, a comprehensive evaluation index system of performance auditing is approved from the literature related to governmental ecological environment. Secondly, the relative weights of the chosen evaluation indexes of performance auditing are calculated by fuzzy AHP method. Furthermore, TOPSIS method is adopted to rank the performance auditing and improve the gaps with five local governments as an empirical example. As a new data analysis method, the results show that fuzzy AHP theoretical model and TOPSIS method has become suitable for use in the evaluation of performance auditing of governmental ecological environment.
\end{abstract}

Keywords: performance auditing, evaluation index system, decision model, governmental ecological environment, TOPSIS, analytic hierarchy process

\section{Introduction}

In response to accelerating global clean-energy race, governmental ecological environment has been heavily advocated over the past decade. Many different theories and methods of performance auditing of governmental ecological environment for conducting a scientific and reasonable valuation have been applied in various academic circles in the last several years (Paydar et al., 2017). Today organizations operate in an ecological environment where performance auditing is continuously changing and increasing in the process of incidental development (Ivanova et al., 2016). Thus, dealing with qualitative information is quite common in various fields such as decision making and prediction (Fero et al., 2013). The fact of the matter is that evaluation process of performance auditing of governmental ecological environment is costly and its adaptation takes too much time so the evaluation cost is too high in many countries (Zanardo et al., 2018). The performance auditing evaluation has become the certain tendency for the government ecological environment (Shi, 2017). With the development of economic reforms, remarkable progress has been made in the efficient use of resources and ecological environment by using performance auditing in the past years in China. Thus, an effective intelligent decision method which automates and integrates evaluation processes and allows information sharing in governmental ecological environment needs to be researched in in-depth (Minichilli et al., 2017; Manzoor et al., 2018). Moreover, making some research on performance auditing of the governmental ecological 
environment is of great significance to find a way to evaluate performance auditing accurately.

On the other hand, it is necessary to supervise and improve the situation of performance auditing by government, and the evaluation of governmental ecological environment is becoming more and more important. The research of comprehensive evaluation index system of performance auditing has been theoretical and practical as the development of scientific technology and economic reform (Gutierrez, 2015). So a theoretical analysis of the objectiveness for evaluation of performance auditing was used to protect the whole governmental ecological environment. Although local governments can develop their own evaluation index system, other ones may prefer ready systems to shorten application cycle and reduce human resource cost (Johansen and Christoffersen, 2017). Therefore the evaluation index system of performance auditing is an important decision making problem of local governments and effects directly the governmental ecological environment (Mueller, 2011). The overall performance auditing must be verified by environmental checkers in the following aspects of implementation measures of governmental ecological environment, environmental monitoring and auditing arrangement and other environmental protection system (Nehme, 2017). Because governmental ecological environment entries propagate to performance auditing, the comprehensive evaluation index system would require more attention and time (Stephenson, 2015). This paper focuses on structuring a decision aid mechanism on the basis of fuzzy AHP and TOPSIS under fuzzy environment in order to route useful decisions with respect to the public satisfaction evaluation of governmental sectors. Furthermore, the fuzzy algorithms are integrated into the decision-making framework in order to involve quantitative information into the performance auditing evaluation.

The remainder of this paper is organized as follows. A comprehensive evaluation index system of performance auditing of governmental ecological environment is built in Section 2. And the concepts of fuzzy AHP and TOPSIS are introduced in this section. In Section 3, the performance auditing evaluation framework and the analytical methods are proposed. The detailed implementation of the evaluation model and process by using fuzzy AHP and TOPSIS method is also given in this section. An empirical example for performance auditing evaluation indexes and the result analyses is presented to illustrate the approved evaluation model and method with five local governments in Section 4. Lastly, concluding remarks and proposals for further research are given in Section 5.

\section{Comprehensive evaluation index system of performance auditing}

In this paper, a fuzzy theory and AHP method is adopted to implement the evaluation process. To use AHP model for the evaluation of performance auditing of governmental ecological environment for a new tool, a new group of expert's opinions are needed as input to the decisions process. The comprehensive evaluation index system of performance auditing is shown in Fig. 1 .

At present, the research on a systematic and complete performance auditing evaluation system is not perfect in practice. This study has attempted to establish a decision mechanism towards the execution of shipping investment decisions based on customer satisfaction levels in different markets. The comprehensive evaluation index system of performance auditing is presented with the analysis of governmental ecological environment affecting factors. As an effective decision tool, the proposed comprehensive evaluation index system of performance auditing is expected to provide invaluable decision for governmental ecological environment. In addition, multi-level 
comprehensive evaluation index system of performance auditing of governmental ecological environment was expounded from the model.

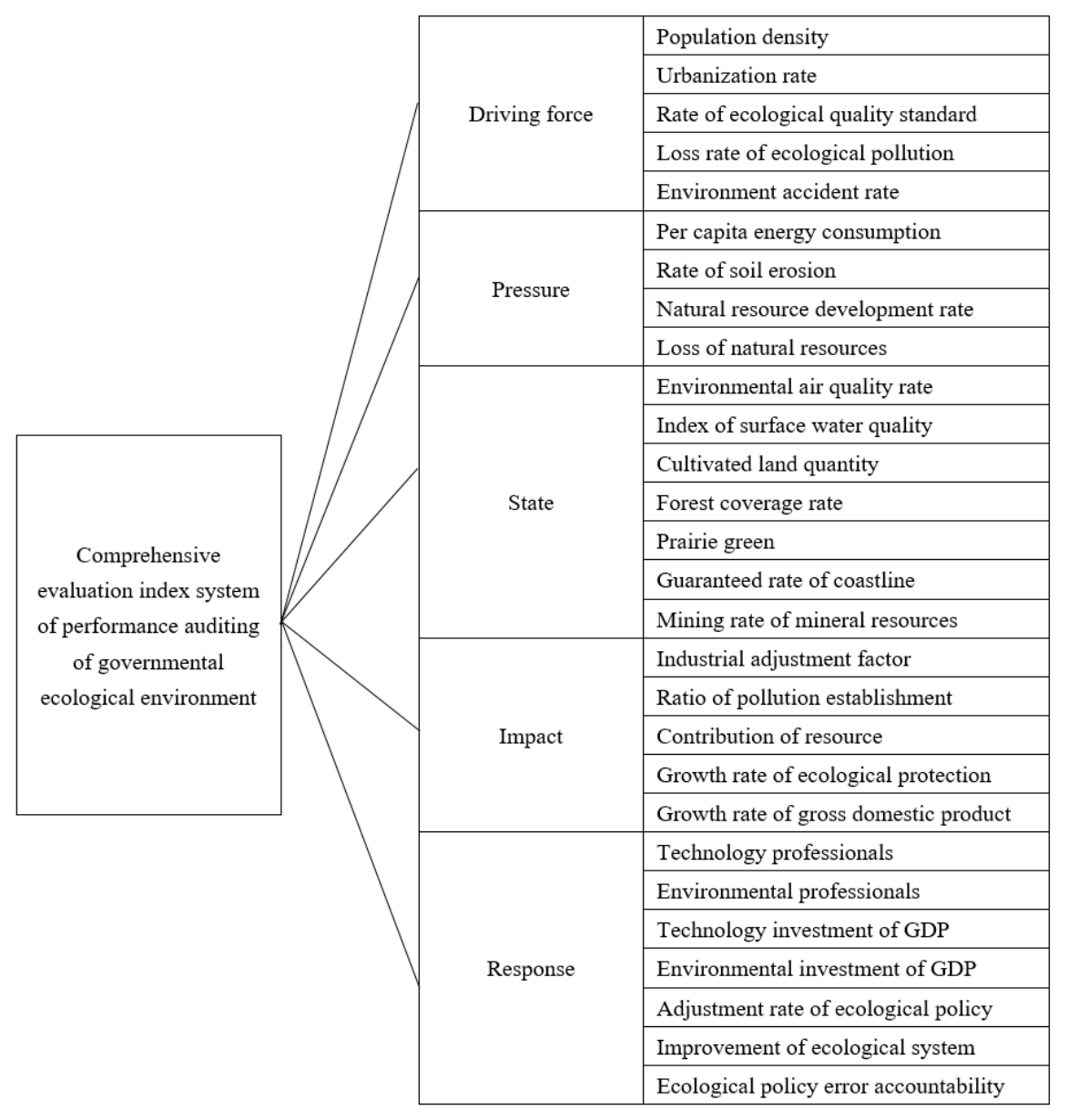

Figure 1. The comprehensive evaluation index system of performance auditing

\section{Research methodology}

\section{Fuzzy analytic hierarchy process}

In this paper, we propose a comprehensive evaluation method of performance auditing consists of integration of fuzzy AHP and TOPSIS. The Analytic Hierarchy Process (AHP) was firstly devised by Wind and Saaty in 1980. It is a useful tool to solve complex decision problems in many fields (Groselj and Stirn, 2018). The relative importance of a list of indexes was presented by using a pairwise comparison amongst the factors by relevant experts (Ahmadipari et al., 2018). In past years, the AHP method has been used often for decision problem, but recently years fuzzy AHP method has been preferred more than AHP method for MCDM problem (Kumar et al., 2017). Moreover, the fuzzy theory has become a useful tool for automating human activities in the decision-making process (Nazari et al., 2018). Fuzzy numbers are often convenient to work with triangular fuzzy numbers in promoting representation and information processing of system theory in a fuzzy environment (Hategekimana, 2018). For example, the decision makers cannot provide a satisfaction value precisely such as 'quite satisfactory' and 'not very 
satisfactory' (Tahri et al., 2017). In here, it is suggested that the decision makers use the different variables to evaluate the importance of the criteria combined with the actual condition.

The evaluation criteria and alternatives as regards the problems of performance auditing of governmental ecological environment presented in this paper have been modeled by using fuzzy AHP. Next, this paper describes the relevant elements of computational steps and the main method of calculating process.

Step 1. Structuring fuzzy judgment matrix

Triangular fuzzy number $\mathrm{M}$ is presented as $(1, \mathrm{~m}, \mathrm{u})$, and $\mu_{\mathrm{M}}(x)$ is given as:

$$
\mu_{\mathrm{M}}(x)= \begin{cases}\frac{1}{m-u} x-\frac{u}{m-u} & x \in[m, u] \\ \frac{1}{m-x} x-\frac{l}{m-l} & x \in[l, m] \\ 0 & \text { other }\end{cases}
$$

where $\mathrm{l} \leq \mathrm{m} \leq \mathrm{u}, 1$ and $\mathrm{u}$ is the lower and upper bound values of $\mathrm{M}$ respectively, which is shown in Fig. 2.

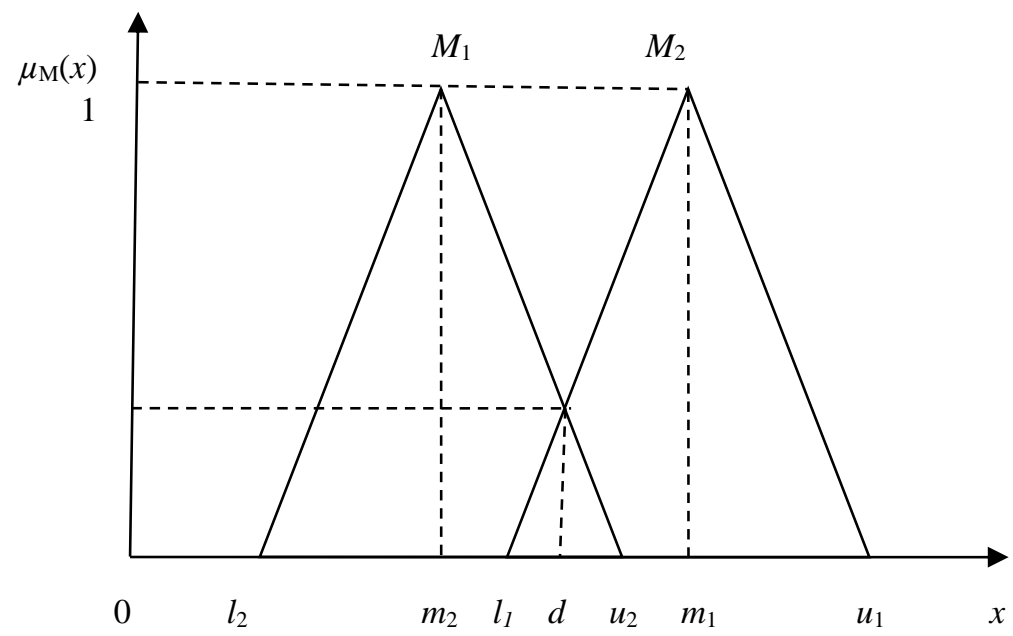

Figure 2. Relationship between fuzzy number M1 and M2

As $M_{1}=\left(l_{1}, m_{1}, u_{1}\right)$ and $M_{2}=\left(l_{2}, m_{2}, u_{2}\right)$ are two triangular fuzzy numbers, the operation methods of two trigonometric fuzzy numbers are presented in the following:

$$
\begin{gathered}
M_{1}+M_{2}=\left(l_{1}+l_{2}, m_{1}+m_{2}, u_{1}+u_{2}\right) \\
M_{1} \otimes M_{2} \approx\left(l_{1} l_{2}, m_{1} m_{2}, u_{1} u_{2}\right) \\
1 / M \approx(1 / u, 1 / m, 1 / l)
\end{gathered}
$$


Step 2. Determining fuzzy number

In order to get the interval solution of the model, all the comparison matrix numbers would be turn into a fuzzy number. The formula to transform various kinds of fuzzy number into triangular ones are given as:

$$
\left(\frac{l_{1}+l_{2}+\cdots+l_{i}}{i}, \frac{m_{1}+m_{2}+\cdots+m_{i}}{i}, \frac{u_{1}+u_{2}+\cdots+u_{i}}{i}\right)
$$

With algorithms, a fuzzy variable will transform the fuzzy number into interval number by using the basic theory of fuzzy numbers.

Step 3. Calculating fuzzy value

In this paper, the definition of a fuzzy value is presented in the following:

$$
D_{\mathrm{i}}^{k}=\sum_{j=1}^{n} a_{i j}^{k} /\left(\sum_{i=1}^{n} \sum_{j=1}^{n} a_{i j}^{k}\right)
$$

where $i=1,2, \ldots, n$.

Step 4. Definition of trigonometric fuzzy functions

As $\mathrm{M} 1 \geq \mathrm{M} 2$, the probability of the triangular fuzzy function is defined as:

$$
\begin{gathered}
V\left(M_{1} \geq M_{2}\right)=\sup _{x \geq y}\left[\min \left(\mu_{M 1}(x), \mu_{M 2}(y)\right)\right] \\
V\left(M_{1} \geq M_{2}\right)=\mu(d)= \begin{cases}\left(l_{2}-u_{1}\right) /\left(\left(m_{1}-u_{1}\right)-\left(m_{2}-l_{2}\right)\right) \quad m_{1} \leq m_{2}, \quad u_{1} \geq l_{2} \\
1 & m_{1} \geq m_{2} \\
0 & \text { otherwise }\end{cases}
\end{gathered}
$$

Step 5. Determining weights of the level indicators

If a fuzzy number is greater than the probability of other fuzzy numbers, it is given in the following:

$$
V\left(M \geq M_{1}, M_{2}, \ldots \ldots, M_{n}\right)=\min V\left(M \geq M_{i}\right)
$$

Step 6. Calculating the weight vectors

Assume that $\mathrm{d}(\mathrm{Ai})=\operatorname{minV}(\mathrm{Si} \geq \mathrm{Sk})$, and $\mathrm{k}=1,2, \ldots, \mathrm{n}$. the fuzzy theory was used to determine the weight vector of each index, which can be defined by

$$
W^{\prime}=\left(d^{\prime}\left(A_{1}\right), d^{\prime}\left(A_{2}\right), \cdots, d^{\prime}\left(A_{n}\right)\right)^{T}
$$

where $\mathrm{Ai}(\mathrm{i}=1,2, \ldots, \mathrm{n})$ are $\mathrm{n}$ elements of a situation.

Next, the normalized weight vectors with different optimum indicators are expressed as follows:

$$
W=\left(d\left(A_{1}\right), d\left(A_{2}\right), \cdots, d\left(A_{n}\right)\right)^{T}
$$

Thus, the calculation method obtained from above results can be used to accurately determine the comprehensive weight of each index. 


\section{Technique for order preference by similarity to ideal solution}

TOPSIS (Technique for Order Preference by Similarity to Ideal Solution) is one of the useful tools to solve real-world problems of quantitative and qualitative factors including economic and social factors (Deveci et al., 2018). TOPSIS makes it possible to appraise the distances of each indicators from the positive and negative ideal solutions by comparing the difference among many schemes (Wang et al., 2017; Korucu et al., 2018). The positive ideal solution is composed of all best values in the decision making process (Hussain and Yang, 2018). Furthermore, the sorting of schemes and weights are very straight forward and clear. In the process of TOPSIS method, the performance ratings and the weights of each criteria are given more verbose output (Kaur et al., 2018). The TOPSIS is an extensive and thorough decision tool to evaluate the performance auditing in different fields (Lourenzutti et al., 2017; Gupta, 2018). With respect to MCDM problem in which both the attribute weights and attribute values are fuzzy numbers, a new method of TOPSIS is presented in this paper.

Assume that a multiple criteria decision-making problem with $m$ alternatives $A_{1}, A_{2}, \cdots, A_{m}$ and $n$ decision attributes $D_{1}, D_{2}, \cdots, D_{n}$, and the decision matrix is defined in Table 1.

Table 1. The decision matrix of multiple criteria decision-making problem

\begin{tabular}{c|c|c|c|c}
\hline No. & $D_{1}$ & $D_{2}$ & $\cdots$ & $D_{n}$ \\
\hline$A_{1}$ & $x_{11}$ & $x_{12}$ & $\cdots$ & $x_{1 n}$ \\
$A_{2}$ & $x_{21}$ & $x_{22}$ & $\cdots$ & $x_{2 n}$ \\
$\ldots$ & $\ldots$ & $\ldots$ & $\ldots$ & $\cdots$ \\
$A_{m}$ & $x_{m 1}$ & $x_{m 2}$ & $\cdots$ & $x_{m n}$ \\
\hline
\end{tabular}

Step 1. Computing canonical decision matrix

The multilevel matrix is modeled and simulated in the following:

$$
y_{i j}^{\prime}= \begin{cases}y_{i j} & \text { income-typeinde } \\ -y_{i j} & \text { cost-typeind } \\ 1-y_{i j} & \text { others }\end{cases}
$$

The indexes are evaluated by each decision maker, and are converted into proper variables, which can be defined by

$$
Z_{i j}=x_{i j} / \sqrt{\sum_{i=1}^{m} x_{i j}^{2}}
$$

Step 2. Calculating weighted canonical decision matrix

With the help of the object weight vector, the weighted canonical decision matrix of the alternatives is defined as 


$$
V_{i j}=W_{j} \cdot n_{i j}
$$

where $\sum_{j=1}^{n} W_{j}=1$, which can be determined by using fuzzy AHP method.

Step 3. Determining positive ideal solution (PIS) and negative ideal solution (NIS)

$$
\begin{aligned}
& A^{+}=\left\{V_{1}^{+}, V_{2}^{+}, \cdots, V_{n}^{+}\right\}=\left\{\left(\max V_{i j} \mid j \in I\right),\left(\min V_{i j} \mid j \in I\right)\right\} \\
& A^{-}=\left\{V_{1}^{-}, V_{2}^{-}, \cdots, V_{n}^{-}\right\}=\left\{\left(\min V_{i j} \mid j \in I\right),\left(\max v_{i j} \mid j \in I\right)\right\}
\end{aligned}
$$

where, I belongs to benefit attribute, $\mathrm{j}$ belongs to cost attribute.

Step 4. Calculating the distance of each alternative from PIS and NIS

The distance of each alternative from PIS and NIS are determined:

$$
\begin{aligned}
& d_{i}^{+}=\sqrt{\sum_{j=1}^{n}\left(V_{i j}-V_{j}^{+}\right)^{2}} \\
& d_{i}^{-}=\sqrt{\sum_{j=1}^{n}\left(V_{i j}-V_{j}^{-}\right)^{2}}
\end{aligned}
$$

Step 5. Calculating the closeness coefficient of each alternative

The closeness coefficient of each alternative is given by

$$
C_{i}^{*}=\frac{d_{i}^{-}}{d_{i}^{+}+d_{i}^{-}}
$$

where $i=1,2, \cdots, m$.

Then, the ranking of alternatives can be designed by comparing $C * i$ values.

In this paper, we present TOPSIS method and fuzzy AHP to analyze decision objects, it would make the result to be more reasonable and accurate.

\section{Results}

The aim of this paper is to evaluate the performance auditing of governmental ecological environment of five local governments in Fujian Province of China. The comprehensive evaluation index system and method are applied to assessing performance auditing in part of the local government of Fujian province administrative cities as one example. Firstly, the comprehensive evaluation index system was set up in allusion to the ecological environment of the five local governments by using the method of multifactorial evaluation method of fuzzy mathematics. Based on analysis mode and characteristics of comprehensive evaluation index system, the hierarchy structure of comprehensive evaluation index system was established in a very powerful way. Then, 
many decision makers from different areas evaluate the importance of evaluation indexes with the help of questionnaires. Next, the performance auditing was built and the traditional method of AHP is improved with fuzzy theory, which was also utilized for determining the weights of main evaluation criteria. Finally, TOPSIS method was presented for evaluating the performance auditing of governmental ecological environment by considering ecological efficiency and weights of the criteria. According to above methods, the ranking of the performance auditing can be obtained by improvement of the given model and method in the numerical example.

Based on fuzzy AHP method, the hierarchical structure of performance auditing of model in application is shown in Fig. 3.

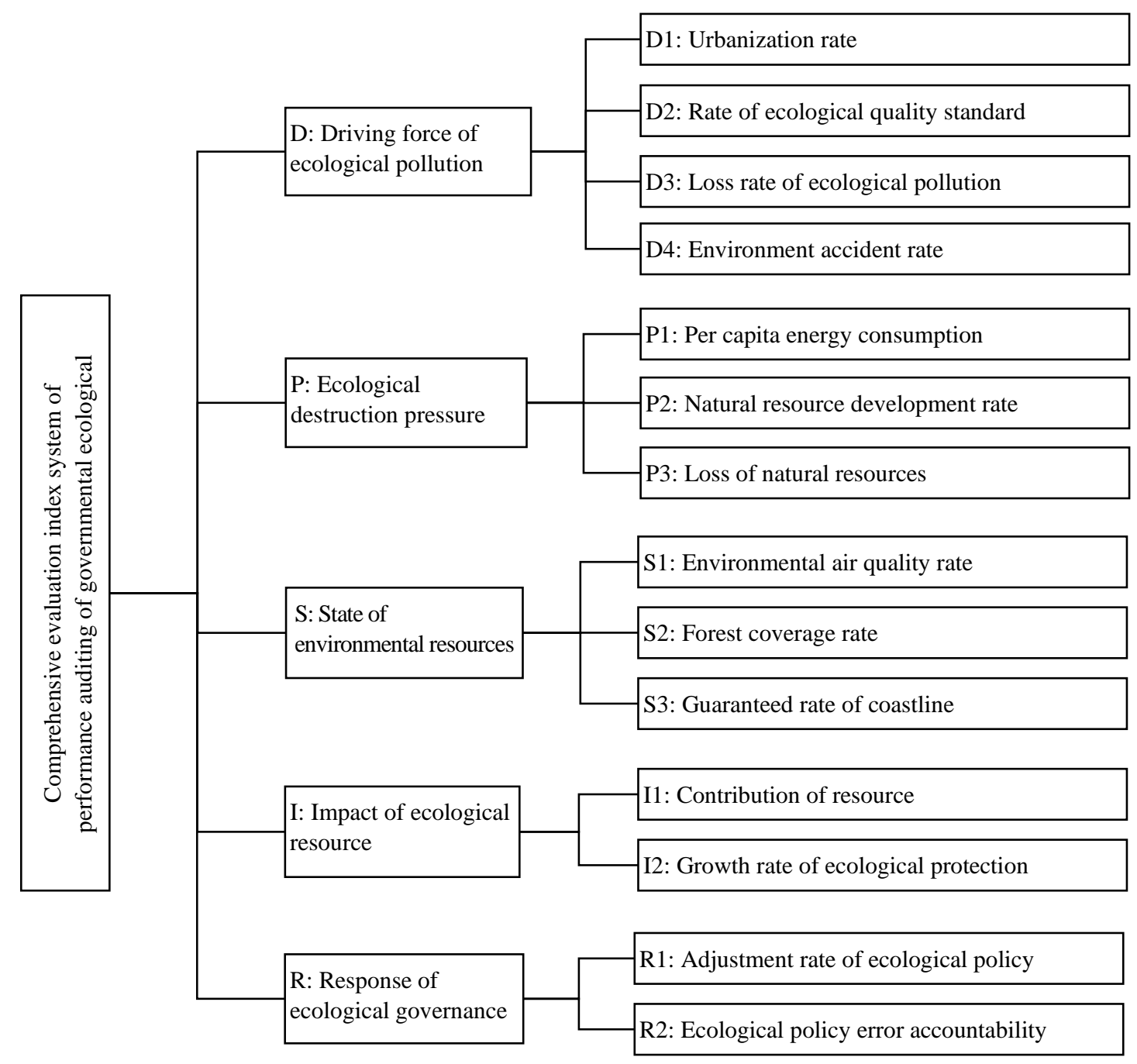

Figure 3. Hierarchical structure of performance auditing of model in application

The decision of fuzzy AHP is an interactive evaluation system intended to help decision makers from different backgrounds compile useful information from different weight vectors to make decisions. The data extraction process includes combinations of qualitative and quantitative data analysis, questionnaires, interviews, scoring by many experts from Fujian province administrative cities in China. For the purpose of 
determining the correlation between evaluation criterions more accurately and faster than ever before, we determine relative importance of each criteria over another based on pairwise comparison by a group decision. Thus, each decision maker individually can make out pair-wise comparison by using 1-9 scale.

In this paper, we take the evaluation index of ecological destruction pressure $(\mathrm{P})$ as example, the mathematical model and solution procedure for performance auditing of governmental ecological environment are briefly depicted, which includes sub-indicator of per capita energy consumption (P1), natural resource development rate (P2) and loss of natural resources (P3). The pair-wise comparison matrix is show by using Eq. 1 in the following:

$$
\begin{array}{|ccccccccc|}
1 & 1 & 1 & 3 & 2 & 2 & 1 & 1 & 2 \\
1 & 1 & 1 & 2 & 3 & 4 & 2 & 1 & 2 \\
1 & 1 & 1 & 4 & 1 & 2 & 1 & 2 & 3 \\
1 / 2 & 1 / 2 & 1 / 3 & 1 & 1 & 1 & 1 & 1 & 2 \\
1 / 4 & 1 / 3 & 1 / 2 & 1 & 1 & 1 & 1 & 2 & 3 \\
1 / 2 & 1 & 1 / 4 & 1 & 1 & 1 & 8 & 1 & 7 \\
1 / 2 & 1 & 1 & 1 / 2 & 1 & 1 & 1 & 1 & 1 \\
1 / 2 & 1 & 1 / 2 & 1 / 3 & 1 / 2 & 1 & 1 & 1 & 1 \\
1 / 3 & 1 / 2 & 1 & 1 / 7 & 1 & 1 / 8 & 1 & 1 & 1
\end{array} \mid
$$

Based on triangular fuzzy number judgment matrix theory and priority method, the fuzzy pair-wise comparison matrix is transformed into triangular fuzzy numbers by using Eq. 2, Eq. 3 and Eq. 4, which is given as

$$
\left|\begin{array}{lllllllll}
1.000 & 1.000 & 1.000 & 3.000 & 2.000 & 2.667 & 1.333 & 1.333 & 2.333 \\
0.417 & 0.611 & 0.361 & 1.000 & 1.000 & 1.000 & 3.333 & 1.333 & 4.000 \\
0.444 & 0.833 & 0.833 & 0.325 & 0.833 & 0.708 & 1.000 & 1.000 & 1.000
\end{array}\right|
$$

By using fuzzy pair-wise comparison matrix, the synthesis values of different evaluation indexes can be calculated in the following:

$$
\left|\begin{array}{lll}
5.333 & 4.333 & 6.000 \\
4.750 & 2.944 & 5.361 \\
1.770 & 2.667 & 2.542
\end{array}\right|
$$

Next, the complementary index set is composed of the evaluation indexes, which is given as

$$
\begin{array}{|lll}
0.384 & 0.436 & 0.506 \\
0.342 & 0.296 & 0.452 \\
0.127 & 0.268 & 0.214
\end{array} \mid
$$


Then, the synthesis values respect to main goal can be calculated using the system and load characteristics in the following:

$\mathrm{V}(\mathrm{S} 1 \geq \mathrm{S} 2)=1.000, \mathrm{~V}(\mathrm{~S} 1 \geq \mathrm{S} 3)=1.000$.

Then, $\mathrm{d}^{\prime}(\mathrm{C} 1)=\min (1.000,1.000)=1.0000$.

$\mathrm{V}(\mathrm{S} 2 \geq \mathrm{S} 1)=0.330, \mathrm{~V}(\mathrm{~S} 2 \geq \mathrm{S} 3)=1.000$.

Then, $\mathrm{d}^{\prime}(\mathrm{C} 2)=\min (0.330,1.000)=0.3296$.

$\mathrm{V}(\mathrm{S} 3 \geq \mathrm{S} 1)=106.446, \mathrm{~V}(\mathrm{~S} 3 \geq \mathrm{S} 2)=1.281$.

Then, $\mathrm{d}^{\prime}(\mathrm{C} 3)=\min (106.446,1.281)=1.281$.

Thus, we can obtaine the values priority weights respect to main goal, which is given as

$\mathrm{W}=(0.383,0.126,0.491)$.

In the same way, we can calculate other weights of evaluation index of performance auditing of governmental ecological environment with similarity calculation method. So weights of sub-criteria to illustrate the steps used to evaluate five local governments are shown in Table 2.

Table 2. The weights of multiple evaluation criteria

\begin{tabular}{|c|c|c|c|}
\hline Evaluation criteria & Local weights & Over weights & Rank \\
\hline (D) Driving force of ecological pollution & 0.358 & 0.358 & 1 \\
\hline (D1) Urbanization rate & 0.138 & 0.049 & 10 \\
\hline (D2) Rate of ecological quality standard & 0.187 & 0.067 & 8 \\
\hline (D3) Loss rate of ecological pollution & 0.372 & 0.133 & 1 \\
\hline (D4) Environment accident rate & 0.303 & 0.108 & 2 \\
\hline (P) Ecological destruction pressure & 0.217 & 0.217 & 2 \\
\hline (P1) Per capita energy consumption & 0.383 & 0.083 & 5 \\
\hline (P2) Natural resource development rate & 0.126 & 0.027 & 14 \\
\hline (P3) Loss of natural resources & 0.491 & 0.107 & 4 \\
\hline (S) State of environmental & 0.106 & 0.106 & 5 \\
\hline (S1) Environmental air quality rate & 0.273 & 0.029 & 13 \\
\hline (S2) Forest coverage rate & 0.321 & 0.034 & 12 \\
\hline (S3) Guaranteed rate of coastline & 0.406 & 0.043 & 11 \\
\hline (I) Impact of ecological resource & 0.173 & 0.173 & 3 \\
\hline (I1) Contribution of resource & 0.384 & 0.066 & 9 \\
\hline (I2) Growth rate of ecological protection & 0.616 & 0.107 & 3 \\
\hline (R) Response of ecological governance & 0.146 & 0.146 & 4 \\
\hline (R1) Adjustment rate of ecological policy & 0.473 & 0.069 & 7 \\
\hline (R2) Ecological policy error accountability & 0.527 & 0.077 & 6 \\
\hline
\end{tabular}

Thus, the weights of multiple criteria of the comprehensive evaluation index system of performance auditing of governmental ecological environment is shown in Fig. 4.

In subsequent sections, we discuss how TOPSIS method is used for comprehensive evaluation of performance auditing of governmental ecological environment. Based on the survey of five local governments in China, this paper sums up the document data and makes some summary statistics, which is shown in Table 3.

Based on TOPSIS method, the establishing process includes constructing the fuzzy judgment matrix and integrating the weight vector is given in the following. 
By using Eq. 12, we can get the index data after transformed and processed of five local governments, which is shown in Table 4.

Next, data normalization of index classification during system modeling has been given in Table 5.

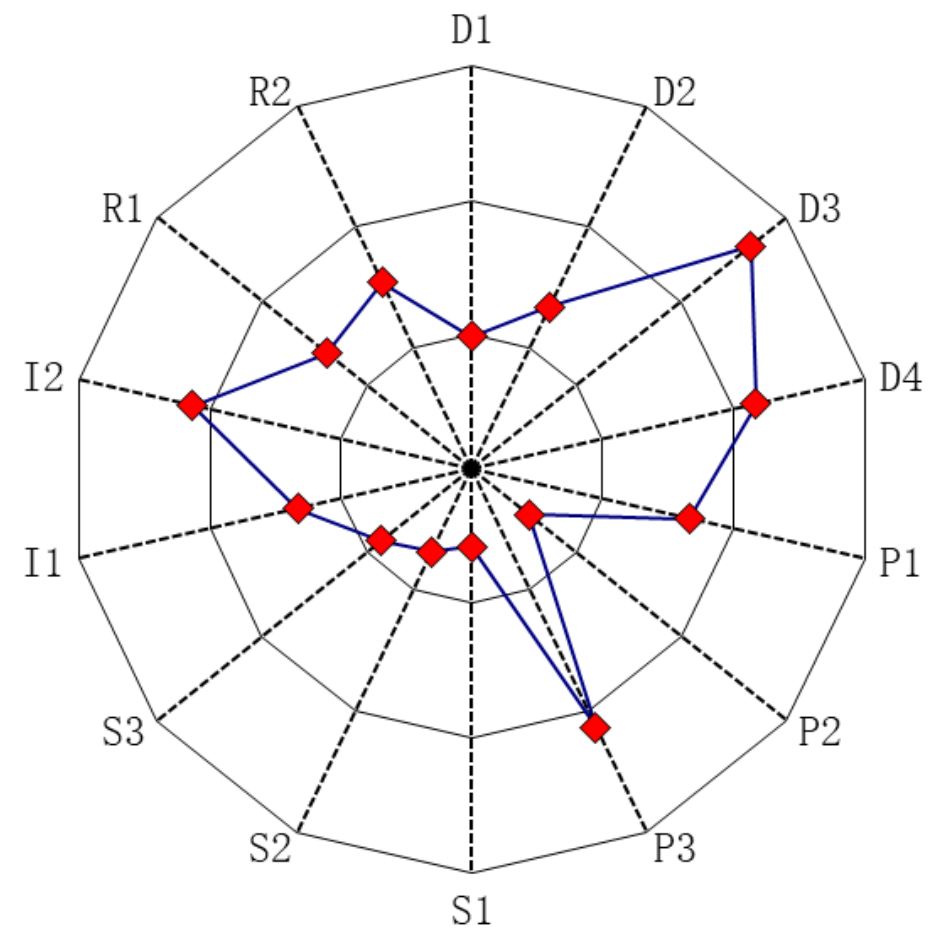

Figure 4. The Spider chart of the weights of comprehensive evaluation indexes

Table 3. The summary statistics of five local governments

\begin{tabular}{c|c|c|c|c|c}
\hline Indexes & $\begin{array}{c}\text { A local } \\
\text { government }\end{array}$ & $\begin{array}{c}\text { B local } \\
\text { government }\end{array}$ & $\begin{array}{c}\text { C local } \\
\text { government }\end{array}$ & $\begin{array}{c}\text { D local } \\
\text { government }\end{array}$ & $\begin{array}{c}\text { E local } \\
\text { government }\end{array}$ \\
\hline D1 & $87 \%$ & $85 \%$ & $76 \%$ & $90 \%$ & $82 \%$ \\
D2 & $98 \%$ & $92 \%$ & $94 \%$ & $88 \%$ & $94 \%$ \\
D3 & $15 \%$ & $10 \%$ & $18 \%$ & $11 \%$ & $19 \%$ \\
D4 & $18 \%$ & $9 \%$ & $21 \%$ & $22 \%$ & $16 \%$ \\
P1 & 2.756 & 2.213 & 2.451 & 2.346 & 2.524 \\
P2 & $21 \%$ & $25 \%$ & $18 \%$ & $28 \%$ & $22 \%$ \\
P3 & $7 \%$ & $10 \%$ & $15 \%$ & $17 \%$ & $11 \%$ \\
S1 & $95 \%$ & $90 \%$ & $91 \%$ & $89 \%$ & $96 \%$ \\
S2 & $78 \%$ & $70 \%$ & $82 \%$ & $72 \%$ & $86 \%$ \\
S3 & 9.5 & 7.6 & 8.2 & 6.4 & 8.8 \\
I1 & $90 \%$ & $87 \%$ & $95 \%$ & $91 \%$ & $93 \%$ \\
I2 & $81 \%$ & $88 \%$ & $78 \%$ & $85 \%$ & $82 \%$ \\
R1 & $12 \%$ & $9 \%$ & $10 \%$ & $7 \%$ & $8 \%$ \\
R2 & $91 \%$ & $94 \%$ & $96 \%$ & $88 \%$ & $92 \%$ \\
\hline
\end{tabular}


Table 4. The index data after transformed and processed of five local governments

\begin{tabular}{c|c|c|c|c|c}
\hline Indexes & $\begin{array}{c}\text { A local } \\
\text { government }\end{array}$ & $\begin{array}{c}\text { B local } \\
\text { government }\end{array}$ & $\begin{array}{c}\text { C local } \\
\text { government }\end{array}$ & $\begin{array}{c}\text { D local } \\
\text { government }\end{array}$ & $\begin{array}{c}\text { E local } \\
\text { government }\end{array}$ \\
\hline D1 & 0.870 & 0.850 & 0.760 & 0.900 & 0.820 \\
D2 & 0.980 & 0.920 & 0.940 & 0.880 & 0.940 \\
D3 & 0.850 & 0.900 & 0.820 & 0.890 & 0.810 \\
D4 & 0.820 & 0.910 & 0.790 & 0.780 & 0.840 \\
P1 & 2.756 & 2.213 & 2.451 & 2.346 & 2.524 \\
P2 & 0.790 & 0.750 & 0.820 & 0.720 & 0.780 \\
P3 & 0.930 & 0.900 & 0.850 & 0.830 & 0.890 \\
S1 & 0.950 & 0.900 & 0.910 & 0.890 & 0.960 \\
S2 & 0.780 & 0.700 & 0.820 & 0.720 & 0.860 \\
S3 & 9.500 & 7.600 & 8.200 & 6.400 & 8.800 \\
I1 & 0.900 & 0.870 & 0.950 & 0.910 & 0.930 \\
I2 & 0.810 & 0.880 & 0.780 & 0.850 & 0.820 \\
R1 & 0.880 & 0.910 & 0.900 & 0.930 & 0.920 \\
R2 & 0.910 & 0.940 & 0.960 & 0.880 & 0.920 \\
\hline
\end{tabular}

Table 5. The data normalization of five local governments

\begin{tabular}{c|c|c|c|c|c}
\hline Indexes & $\begin{array}{c}\text { A local } \\
\text { government }\end{array}$ & $\begin{array}{c}\text { B local } \\
\text { government }\end{array}$ & $\begin{array}{c}\text { C local } \\
\text { government }\end{array}$ & $\begin{array}{c}\text { D local } \\
\text { government }\end{array}$ & $\begin{array}{c}\text { E local } \\
\text { government }\end{array}$ \\
\hline D1 & 0.462 & 0.452 & 0.404 & 0.478 & 0.436 \\
D2 & 0.470 & 0.441 & 0.451 & 0.422 & 0.451 \\
D3 & 0.445 & 0.471 & 0.429 & 0.466 & 0.424 \\
D4 & 0.442 & 0.491 & 0.426 & 0.421 & 0.453 \\
P1 & 0.500 & 0.402 & 0.445 & 0.426 & 0.458 \\
P2 & 0.457 & 0.434 & 0.475 & 0.417 & 0.451 \\
P3 & 0.472 & 0.457 & 0.432 & 0.421 & 0.452 \\
S1 & 0.461 & 0.436 & 0.441 & 0.431 & 0.465 \\
S2 & 0.448 & 0.402 & 0.471 & 0.414 & 0.494 \\
S3 & 0.520 & 0.416 & 0.449 & 0.350 & 0.482 \\
I1 & 0.441 & 0.426 & 0.466 & 0.446 & 0.456 \\
I2 & 0.437 & 0.475 & 0.421 & 0.459 & 0.443 \\
R1 & 0.433 & 0.448 & 0.443 & 0.458 & 0.453 \\
R2 & 0.441 & 0.456 & 0.465 & 0.427 & 0.446 \\
\hline
\end{tabular}

Then, the distance of each local government from PIS and NIS with respect to each criterion are calculated with the help of basic principles and methods of TOPSIS.

The ranking of the five local governments is shown as

$C^{*}=(0.804,0.475,0.361,0.197,0.652)$.

Moreover, the ranking result of the five local governments is shown in Fig. 5. 
Based on $C^{*}$ values, the ranking of the evaluation alternatives in descending order are A, E, B, C and D. Proposed model results indicate that A local government is the best alternative with $\mathrm{C}^{*}$ value of 0.804 . The result is a fundamental measure for raising the evaluation quality, which auditors can also put forward adequate audit findings and audit conclusions.

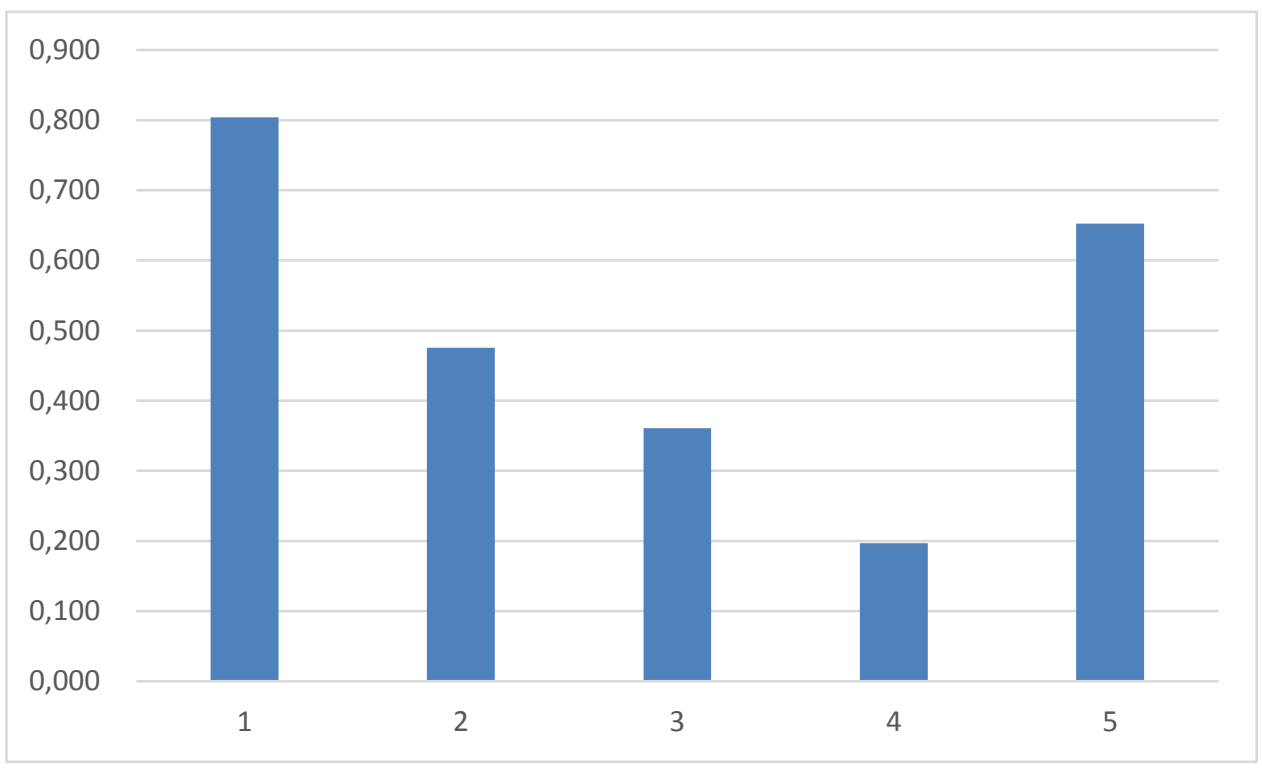

Figure 5. The ranking results of the five local governments

\section{Discussion and implications}

This Innovative Comprehensive Evaluation Index System is an Effective Means to the Performance Auditing of Governmental Ecological Environment in China

In this paper, we find that the comprehensive evaluation index system of performance auditing can better solve the dilemmas faced by China's governmental ecological environment. A comprehensive index system based on fuzzy AHP model is presented in this paper. AHP can be used to solve MCDM problem in many areas, so it has good applicability. Based on establishment of evaluation index system, AHP model is applied to realize the scientific computation on performance auditing of governmental ecological environment in china. This paper also based upon the comprehensive evaluation index system of fuzzy AHP model to come to a good conclusion, which corresponds to the actual case.

\section{This Innovative Method Can Enrich the Evaluation Veracity and Efficiency of Performance Auditing}

Based on fuzzy AHP and TOPSIS method to analyze and solve the evaluation problem is an innovative way to enrich the quality of performance auditing scientifically. The evaluation index system is put forward and the expert system based on AHP is established, so as to solve the evaluation problem of performance auditing combined with TOPSIS method effectively. And the evaluation process are divides into five levels and associates them with evaluating values to solve the problem of index standards for different policies governmental ecological environment. Finally, the result of the case in 
Fujian Province of China shows that the improved method, this innovative method with fuzzy AHP and TOPSIS method increases the evaluation's veracity and efficiency of the comprehensive evaluation system.

\section{This New Model of Performance Auditing Contributes to the Sustainable Development of Governmental Ecological Environment in China}

Through our investigations, we can see that government and people have indicated that it gains the great benefits to take action to solve the ecological environment in China. Constructed intelligent evaluation technology that combines together of performance auditing and governmental ecological environment, it has extensive application prospects in sustainable development status on the scales of the Fujian Province and the whole country. This paper explains the meaning of sustainable development, analyses the importance of evaluating performance auditing of governmental ecological environment, and proposed the corresponding countermeasure.

\section{Conclusions}

The performance auditing evaluation of governmental ecological environment has become the important part of government auditing in many developed countries. This study mainly focused on discussing the theory feasibility by using the comprehensive evaluation index system of governmental ecological environment in performance auditing evaluation process. The performance auditing evaluation of governmental ecological environment is a synthetic analysis process from the macro-point of view. This paper gives some useful suggestion in the application of performance auditing evaluation system. Moreover, the solution is performed by using decision-making algorithms under fuzzy evaluation environment. In this paper, we extended the concept of fuzzy AHP and TOPSIS to develop a new method for solving MCDM problems in fuzzy environment. The comprehensive evaluation index system is built by using the concept and trait of performance auditing. Therefore, the proposed evaluation framework overcomes the various difficulties during the decision process of decision-making. In this paper, the illustrative application of the approved model was performed on the base of complex classification and processing. Moreover, the research methodology of this paper is established on the basis of fuzzy theory, AHP theoretical model and TOPSIS method. The results show that the comprehensive approach of evaluation index system has better decision precision and adaptability. This research is of significance not only to performance auditing of the governmental ecological environment, but also to performance auditing of other government environment protection policy. For future work, if the approved methods combining with other intelligent decision making techniques can be successfully applied to the evaluation system, then the decision efficiency and accuracy will be effectively increased.

Acknowledgements. This work was supported by the National Social Science Foundation in China (19BJY033); Ministry of Education Industry and Education Integration Project in China (201802154075); Major Social Science Planning Projects in Fujian Province (FJ2018JDZ014);Wenzhou Basic Scientific Research Project (R20190019 and R20190023); Zhejiang Social Sciences Planning Project (18NDJC128YB); Soft Science Project of Zhejiang Province (2020C35025); Wenzhou Social Sciences Planning Project (19wsk215 and 19wsk216); The Project of Culture Department in Zhejiang Province (zw2018052). 


\section{REFERENCES}

[1] Ahmadipari, M., Hoveidi, H., Jafari, H. R., Pazoki, M. (2018): An integrated environmental management approach to industrial site selection by genetic algorithm and fuzzy analytic hierarchy process in geographical information system. - Global Journal of Environmental Science and Management-Gjesm 4(3): 339-350.

[2] Deveci, M., Canitez, F., Gokasar, I. (2018): WASPAS and TOPSIS based interval Type-2 fuzzy MCDM method for a selection of a car sharing station. - Sustainable Cities and Society 41: 777-791.

[3] Fero, J., Duncan, D. H., Spry, S. (2013): Evaluating the performance of a centralised government geodatabase in capturing publicly-funded natural resource management activities in Victoria, Australia. - Australasian Journal of Environmental Management 20(2): 101-115.

[4] Fleming, R. A., Barclay, H. J., Candau, J. N. (2002): Scaling-up an autoregressive timeseries model (of spruce budworm population dynamics) changes its qualitative behaviour. - Ecological Modelling 149(1-2): 127-142.

[5] Groselj, P., Stirn, L. Z. (2018): Evaluation of several approaches for deriving weights in fuzzy group analytic hierarchy process. - Journal of Decision Systems 27: 217-226.

[6] Gupta, H. (2018): Assessing organizations performance on the basis of GHRM practices using BWM and fuzzy TOPSIS. - Journal of Environmental Management 226: 201-216.

[7] Gutierrez, L. A. (2015): The supreme audit at subnational level in Mexico: a performance's evaluation of the local supreme audit institutions (SAIs). - Revista Mexicana De Analisis Politico Y Administracion Publica 4(2): 141-165.

[8] Hategekimana, Y., Yu, L., Nie, Y., Zhu, J., Liu, F., Guo, F. (2018): Integration of MultiParametric fuzzy analytic hierarchy process and GIS along the UNESCO world heritage: a flood hazard index, Mombasa County, Kenya. - Natural Hazards 92(2): 1137-1153.

[9] Hussain, Z., Yang, M. S. (2018): Entropy for hesitant fuzzy sets based on Hausdorff metric with construction of hesitant fuzzy TOPSIS. - International Journal of Fuzzy Systems 20(8): 2517-2533.

[10] Ivanova, D., Haradinova, A., Vasileva, E. (2016): Environmental performance of companies with environmental management systems in Bulgaria. - Quality-Access to Success 17(152): 61-66.

[11] Johansen, T. R., Christoffersen, J. (2017): Performance evaluations in audit firms: evaluation Foci and dysfunctional behaviour. - International Journal of Auditing 21(1): 2437.

[12] Kaur, R., Singh, S., Kumar, H. (2018): AuthCom: authorship verification and compromised account detection in online social networks using AHP-TOPSIS embedded profiling based technique. - Expert Systems with Applications 113: 397-414.

[13] Korucu, H., Simsek, B., Yartasi, A. (2018): A TOPSIS-based Taguchi design to investigate optimum mixture proportions of Graphene Oxide powder synthesized by hummers method. - Arabian Journal for Science and Engineering 43(11): 6033-6055.

[14] Kumar, K. A., Kumar, P. S., Madhusudanan, S., Pasupathy, V., Vignesh, P. R., Sankaranarayanan, A. R. (2017): A simplified model for evaluating best biodiesel production method: fuzzy analytic hierarchy process approach. - Sustainable Materials and Technologies 12: 18-22.

[15] Lourenzutti, R., Krohling, R. A., Reformat, M. Z. (2017): Choquet based TOPSIS and TODIM for dynamic and heterogeneous decision making with criteria interaction. Information Sciences 408: 41-69.

[16] Manzoor, R., Zhang, T., Zhang, X., Wang, M., Pan, J. F., Wang, Z., Zhang, B. (2018): Single and combined metal contamination in coastal environments in China: current status and potential ecological risk evaluation. - Environmental Science and Pollution Research 25(2): 1044-1054. 
[17] Minichilli, F., Santoro, M., Bianchi, F., Caranci, N., De Santis, M., Pasetto, R. (2017): Evaluation of the use of the socioeconomic deprivation index at area level in ecological studies on environment and health. - Epidemiologia \& Prevenzione 41(3-4): 187-196.

[18] Mueller, P. (2011): Performance audit and evaluation similarities and differences between the performance audits of the German federal court of audit and evaluations on active labour market policies. - Zeitschrift Fur Evaluation 10(1): 17-38.

[19] Nazari, S., Fallah, M., Kazemipoor, H., Salehipour, A. (2018): A fuzzy inference-fuzzy analytic hierarchy process-based clinical decision support system for diagnosis of heart diseases. - Expert Systems with Applications 95: 261-271.

[20] Nehme, R. (2017): Performance evaluation of auditors: a constructive or a destructive tool of audit output. - Managerial Auditing Journal 32(2): 215-231.

[21] Paydar, L., Firouzi, S., Aminpanah, H. (2017): Energy audit of organic and non-organic olive (Olea europaea L.) production agro-ecosystems in Rudbar region, iron. - Revista De La Facultad De Agronomia De La Universidad Del Zulia 34(4): 497-517.

[22] Podani, J. (1994): Multivariate Data Analysis in Ecology and Systematics. - SPB Publishing, The Hague.

[23] Shi, S. X. (2017): Performance evaluation of urban ecological environment construction with interval-valued intuitionistic fuzzy information. - Journal of Intelligent \& Fuzzy Systems 32(1): 1119-1127.

[24] Stephenson, P. (2015): Reconciling audit and evaluation? the shift to performance and effectiveness at the European court of auditors. - European Journal of Risk Regulation 6(1): 79-89.

[25] Tahri, M., Maanan, M., Maanan, M., Bouksim, H., Hakdaoui, M. (2017): Using fuzzy analytic hierarchy process multi-criteria and automatic computation to analyse coastal vulnerability. - Progress in Physical Geography 41(3): 268-285.

[26] Thompson, J. N. (1984): Insect Diversity and the Trophic Structure of Communities. - In: Huffaker, C. B. (ed.) Ecological Entomology. Wiley-Interscience, New York.

[27] Tóthmérész, B. (1995): Comparison of different methods for diversity ordering. - Journal of Vegetation Science 6: 283-290.

[28] Wang, J., Tang, L., Luo, Y., Ge, P. (2017): A weighted EMD-based prediction model based on TOPSIS and feed forward neural network for noised time series. - Knowledge-Based Systems 132: 167-178.

[29] Wind, Y., Saaty, T. L. (1980): Marketing applications of the analytic hierarchy process. Management Science 26(7): 641-658.

[30] Zanardo, R. P., Mairesse Siluk, J. C., Savian, F. d. S., Smith Schneider, P. (2018): Energy audit model based on a performance evaluation system. - Energy 154: 544-552. 